\title{
Higher Education Academic Resilience: Preparing Your HDR Application
}

\author{
Marie B. Fisher \\ Australian Catholic University \\ Australia
}

\begin{abstract}
What are the preparatory steps in the process of refining a thesis topic, deciding your overarching research question, and commencing your investigation? The aim of the paper is to reflect upon the preliminary process that higher degree research students need to navigate, so that they can ease into the winding road they must travel to complete their thesis. While it is accepted that every student's experience and personal circumstances may be different, this paper provides a reflective exploration of the author's journey which is supported, informed, and guided by literature and educational theories. It will address the impact of the individual's perception of the responsibilities of both supervisor and students, managing work responsibilities, administrative university requirements and consider how these experiences may increase or decrease motivation, and are adjusted, ultimately leading to transformation in learning and practice. By sharing these observations and eliciting feedback from colleagues on resilient strategies they adopted or advised their students to use in their HDR journeys, this research will contribute to a model that will be developed for helping part-time higher degree research students 'stick with it' and achieve success. This reflective practice work is the second part of a work in progress presented in 2020 and published as an extended paper as an introduction in the form of a Reflective overview of the HDR journey, in early 2021.
\end{abstract}

\section{Introduction}

The purpose of this paper is to reflect on the preliminary steps to consider when deciding to embark on a Higher Degree by Research (HDR) Study Program. It is expected that this paper will explore guidance steps for postgraduate students and help them prepare for the experience. In addition, it is expected that the research and practice informed advice will also be a useful framework and checklist for postgraduate research supervisors supporting new researchers.

\section{Background}

Completing a thesis was always a key goal in my academic studies. Despite reading all the books, journal papers and blogs about completing an MPhil and $\mathrm{PhD}$ thesis I was unsure whether I would be able to produce a thesis. I misunderstood the requirements. The Higher Degree by Research (HDR) journey was a mystery. There are many rules and regulations that guide and support the process and completion of one's research thesis that are helpful to the candidate and important to know. However, when one reflects on the experience prior to commencing a thesis it is evident that diverse candidates require different levels and types of support, encouragement, intrinsic motivation, and endurance [1]. An important question to ask yourself is 'Why do I want to study and complete a thesis?' to determine motivation to navigate the twisted, perilous journey. Finishing a thesis is rite of passage to working in academia for many aspiring academics [2].

In addition, one needs to seek an answer to the second question: What are the preparatory steps in the process of refining a thesis topic, deciding your overarching research question, and commencing your investigation? What made my situation different was that I had to navigate and overcome hurdles that I could not have predicted to occur in rapid succession to enable me to alter my perceptions and expectations to commence and complete the thesis [2].

\section{Context}

While contemplating studying for my higher degree I managed to secure a long-term contract with my university, which led to a tenured permanent position [2], [3]. This type of opportunity does not always eventuate when working on contract, so I knew that this was a chance to build and establish an academic career. I had worked as an academic in the past at the Australian National University and the University of Canberra but was limited to academic teaching responsibilities. Therefore, I had experience working as an academic as well as studying part-time [2].

Previously I managed that effectively, so I thought I would be successful. I was encouraged by my Head of School to enrol in a Higher Degree by research. She explained that I needed to gain my $\mathrm{PhD}$ to obtain ongoing employment in a competitive sector of the workforce. However, I soon realised that Academic workloads are substantial, involving teaching, cultivating collaborations, research, meetings as well as substantial academic administration leaving little time for study, let alone production of publications, 
and maintaining regular contact with your HDR supervisors [2], [3]. This paper reflects on the learning experience and informs a flexible approach to understanding and planning to embark on higher degree research.

\section{The Value of Reflection}

Reflection is a process that allows a person to stop, think, evaluate, adjust, change the way you approach tasks and research. It takes practice but it is worth the effort as is a useful form of professional development. It is very helpful in the HDR journey when selfevaluating your progress [2].

Preparation for submission of an HDR application is an important part of the graduate study journey. Once you have successfully navigated the checklist which you develop, based on your preferred university's guidance, you may wish to develop a reflective template. By completing regular reflections using a customised template it will be easier to acknowledge strengths, identify weaknesses, opportunities, and threats to your personal and professional achievements [2].

A reflective approach based on Gibbs, 1988 model of reflection was a framework that the author used in her previous HDR journey to support key learning milestones, obstacles, and opportunities to adjust research approaches, and use with other reflective models [2], [4].

Gibbs' Six Stage model namely: Description of experience; Feelings and thoughts about experiences; Evaluation both positive and negative; Analysis of the experience, such as what one learned; and finally develop an action plan for what a person would do differently to understand the impact arising from the process [4]. For the benefit of those unfamiliar with Gibbs model, one needs to continually evaluate one's output throughout the journey (although it is often forgotten) to assess the impact of your work [2]. There are limitations you may identify when integrating Gibbs' model. His model adopts a clear structure to frame your reflections, however, it does not enable critical reflection beyond practice to explore one's values or offer opportunities to change [5]. A concrete example in the HDR application process would be if your application is rejected, how will you address that failure in the future? Whereas John's approach does allow reflexivity despite being prescriptive [5]. John's model also adopts a series of questions used to evaluate an event. Step 1 is to describe the event. Followed by Step 2 which requires one to reflect on what you intended to achieve. At Step 3 one takes note of the influencing factors. At Step 4 one considers how one could have done it better. When one considers the practical elements required in preparing an HDR application, Kolb's Cycle of Learning may be used to inform and scaffold the key steps. The concrete experience (Step 1) is the process of compiling your application; then reflection on this experience noting any barriers and enablers (Step 2); Abstract conceptualisation (Step 3) helps you determine whether you have grasped what is required by the university to be accepted into a graduate program plus hidden requirements; (Step 4) and finally, consider how you are going to adjust your approach and aspects of your application should you not be accepted into your first choice [6], [2].

The reflective models discussed in this section are just a snapshot of frameworks available to support development of a structured reflection on the HDR application process. The main benefit of using one or more of the models discussed, and educational approaches, will inform how you structure your time, commitment, work, and output when you engage in a research program [2]. This approach is useful to both new and experienced academics. No one size fits all so integrating aspects of reflective models that suit your situation should be applied. It takes practice to change your thinking and engage in this type of scholarship, but it will help you in other aspects of your academic or discipline work in the future [6], [2].

\section{Reflection on the HDR Application Process}

When preparing for the thesis journey I learned to be open minded about how the journey would unfold and progress. It was not a predictable trip as I had shocks on the way due in part to my idealised view of the HDR student journey [2]. However, this experience increased my motivation. Your perceptions of learning, being a student and for people working in academia, will change dramatically over the course of the degree [2]. The pace of this transformative learning and development will be different for all of you. In my study journey Mezirow's Disorientating Dilemma is the thesis [7].

Working through this Disorienting Dilemma changes your thinking, writing and skillset which enable you to articulate a more sequenced argument in your initial research proposal [2]. I regularly reflect on my academic work, personal achievements, network engagement and collaboration to improve my collaboration and output.

In sharing my reflective practice knowledge on the thesis application process, I have integrated aspects of Gibbs' model of reflection to support students and their supervisors through the preliminary steps prior to acceptance into an HDR degree [4]. I will start by describing the situation of applying for a research degree. Most students find the process daunting as it is full of unknown outcomes [8]. When I applied for my first HDR degree I had spoken to potential supervisors, discussed my proposal, felt quite confident about my level of self-direction, and started writing [9]. I had studied previously with my potential supervisor in a postgraduate coursework Masters' 
degree. Therefore, I had developed a working relationship with the supervisor before I applied for the postgraduate research degree. I obtained a reference from two previous postgraduate degree academics, discussed a potential project, applied, and was accepted into the degree. However, I soon became overwhelmed once I had commenced as, unlike undergraduate or postgraduate coursework degrees, there was little direction. The student was expected to drive the work. This was a miscalculation on my part as I had not realised that I needed to advance my learning through engagement with my supervisors either as a colleague or a 'trainee academic' [10]. I assumed that I would be led. I needed a concrete experience and scaffolding to reach the milestones I had set for myself [6]. When I prepared to apply for a second HDR degree recently, I assumed that potential supervisors would be interested in speaking to me about a potential project once I had satisfied the university entry requirements. This was not the case. In hindsight I should have relied on what Knowles would refer to as his Second Principle: Experience [10].

Experience with my own students showed me that potential supervisors need to be convinced to engage with their student's project. The hidden aspect of the application process is the need to 'sell yourself' to a potential supervisor. Try to align with their research interests and show them the benefits of being your HDR supervisor [11].

At the first university I approached, where I had recently studied, I prepared a short, well-structured email requesting supervision. My emails to potential supervisors received a prompt, polite reply stating they did not have time to take on more students.

The second university advised me I had reached stage 1 successfully which was to complete a comprehensive application and provide verified transcripts, a research proposal, a Curriculum Vitae (CV) and supporting statement [12]. However, there was a breakdown in communication and instead of sending me an email explaining the next step within 3 weeks, I had to continually follow up until months later I was asked by the university administration to complete an external student proposal which I did promptly and returned. By this stage the application process had taken six months. I was disappointed that I had wasted all this time when I should have applied to other universities. Therefore, I suggest that you apply to a variety of universities early on. After three months had passed by, I approached the university again about the status of my application. The university administration advised me that the application was with the relevant school in the subject I had applied for. After seven weeks I approached the university again and within two days my application for the $\mathrm{PhD}$ was rejected on the grounds that there was no supervision available for $\mathrm{PhD}$ students at this time. I felt disappointed. Although the Covid 19 pandemic is obviously a factor affecting the ability of universities to provide supervision, I found it extraordinary that I did not receive more feedback. I have learned something important. The transformation occurred for me when I developed awareness of my situation and decided on some decisive action, namely, to adjust my approach in my $\mathrm{PhD}$ applications to universities [13]. Previously I had not been fully aware of the 'hidden' requirements I needed to meet. I still do not know whether I have worked out all the hidden aspects of the application process yet.

At the time of writing this journal paper I am in the process of applying to another three Australian universities to study a research $\mathrm{PhD}$ in Education. If this journey is unsuccessful, I will approach overseas institutions who offer fully online study but charge hefty fees. Despite the best preparation, experience, and motivation sometimes your efforts appear to fall flat.

Academic staff should not be discouraged from applying for a $\mathrm{PhD}$ if your higher degree research application has been rejected. There are other ways to build up your research experience and profile your achievements. Writing collaborations and perseverance when seeking superb mentors will help you improve. I did not know where to start my research journey, so I began attending overseas conferences in the United Kingdom seven years ago [1], [2]. This helped me establish an international reputation in Higher Education Teaching Practice and integration of technology to enhance teaching and, at the same time discover strategies to encourage other colleagues [2]. In addition, I participated in other scholarship of learning and teaching activities such as engaging in reflective practice groups where one can share ideas about effective higher education teaching and professional development, such as the Higher Education Research Association (HERDSA) in Australia.

I had mixed feelings about the application process, after this experience about whether to pursue a $\mathrm{PhD}$ or focus on pursuing my research. However, after considerable reflection and soul searching, I have decided to pursue both and recognise I need to adjust my approach to universities. I do not give up that easily.

My evaluation of the outcome is that Covid 19 has impacted the domestic and international university sector resulting in job losses, reduced capacity to supervise postgraduates and funding shortfalls. I learned that applying to study a $\mathrm{PhD}$ may not be the right time for me at present due in part to this international pandemic and that I may need to provide some more information to potential universities to strengthen my application. As a result of my experience, reflection, and research I wish to offer some suggestions for new HDR students to help them navigate the preliminaries. In the next section I will 
outline the preparation you will need to complete prior to preparing your application.

\section{Preliminary Steps Prior to Commencement of the HDR Journey}

Allocate time to search university websites to find out what HDR programs they offer. Determine if there are additional requirements such as undertaking another MPhil or Research Masters prior to acceptance into a $\mathrm{PhD}$. Once you have narrowed down the universities and programs you wish to apply for you are ready to start your checklist to determine if you are ready to engage in HDR studies. Detailed below is a model to guide students through the HDR application process.

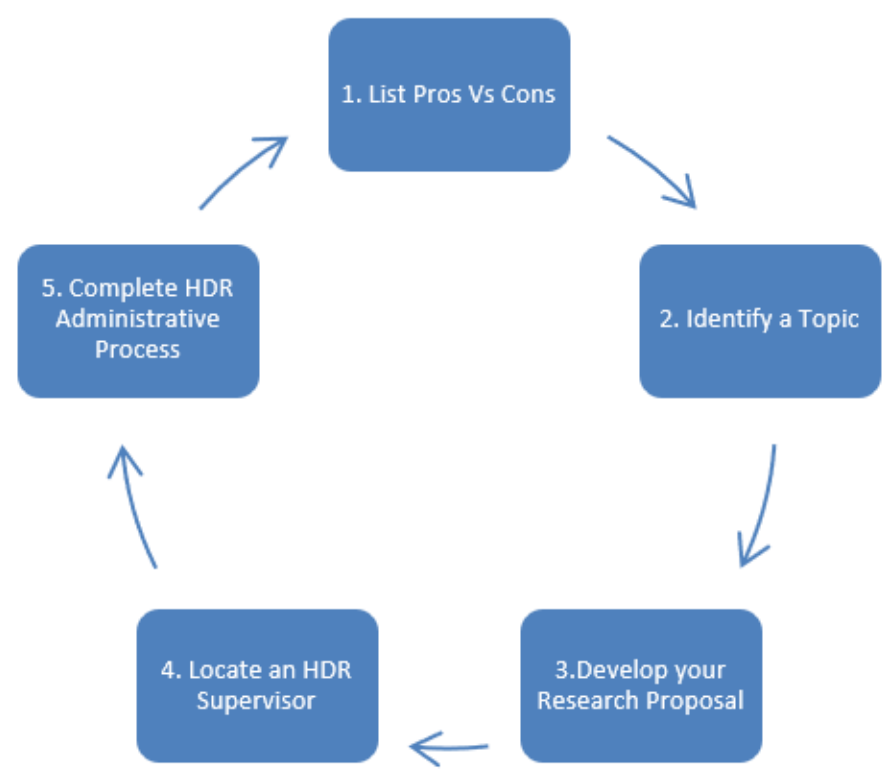

Figure 1. Higher Degree by Research Application Framework Prior to Commencement Flow Chart [Fisher, 2022]

\subsection{List the Pros Vs Cons}

Is a higher degree by research right for me? This was a key question I reflected on at different life stages and in my career. Higher Degree by Research study is different to other types of programs you may have studied. Students will have diverse responsibilities that need to be managed around your degree [14]. Make a list of all the benefits and concerns you have before deciding to undertake a Higher Degree by Research. Consider the time commitment involved. Will there be enough time to fulfil your responsibilities and interests? What about your motivation? Have you considered how you will keep motivated to continue when there are impediments to study such as illness, injury, family responsibilities or you are unable to obtain support from your supervisor [2]? Have a general back up plan with a guide to what you will do if these challenges impede your study and progress through the program. To succeed in a HDR project such as an MPhil or a $\mathrm{PhD}$ you need to have a small, resilient network of supporters whom you can speak with about the proposed project [2], [15]. Never underestimate the power of having a network or even one person who figuratively stands behind you, reminding you that you can do this.

\subsection{Identify a Topic}

There are different approaches to finding a topic and formulating a research question that appeals to you enough that you feel you can sustain your interest for 4-8 years, depending on whether you study full or part-time. Your overall question and sub questions will change during the thesis. No one size fits all. The best way to start is to read as much as you can and make notes about the topic. A research question will emerge when you realise there is a gap in the literature. Here is an example from my thesis in Byzantine history that shows how the topic: Imperial Women's Power in the Sixth century, can be broken down into research questions. The draft research question 1 aligns with the proposed, first content chapter of this thesis. 
Table 1: Narrowing the Topic and Formulating Your Research Questions

\begin{tabular}{|l|l|l|}
\hline \multicolumn{1}{|c|}{ Broad approach } & \multicolumn{1}{|c|}{$\begin{array}{c}\text { Overall research question } \\
\text { arising out of the literature }\end{array}$} & \multicolumn{1}{|c|}{ Research question 1 } \\
\hline $\begin{array}{l}\text { Topic: Byzantine } \\
\text { Empresses and Power in } \\
\text { the Sixth Century }\end{array}$ & $\begin{array}{l}\text { How did Byzantine } \\
\text { empresses access power and } \\
\text { use their influence in the } \\
\text { Sixth Century? }\end{array}$ & $\begin{array}{l}\text { What strategies did Byzantine empresses adopt to access } \\
\text { power and influence through their family and networks in the } \\
\text { Sixth century? }\end{array}$ \\
\hline
\end{tabular}

\subsection{Develop Your Research Proposal}

Books and papers will help inform development of your research questions. The Step Wise Approach is a good place to start. Ratan et. al, 2019 maintains that a good research question is an asset as it informs and helps you sequence your thesis [16]. It is important to develop and include a problem statement specified at the beginning of your thesis. This statement should articulate precisely the problem that you are investigating. Prior to commencing your thesis, you may formulate a statement that describes and narrows down the issue. It will change over time. Your principal supervisor will help you refine it once you commence. Problem statements should add focus, guides data collection, evaluation of findings and establishes your context. In my first thesis the problem statement changed during my research [17].

To formulate your question try using this approach. The key to writing well developed research questions is to be precise. There is considerable literature on this topic to support you and these are areas where you can ask your supervisor for assistance. In my own case I struggled to develop and redevelop research questions for the thesis. However, with support from my principal supervisor about the process of developing questions I was able to redevelop an overarching research question and sub questions which aligned with the thesis chapters [2].

Prior to commencement research questions will change and by the time you finish the thesis you will have more precise questions framing the project. Be prepared to be flexible about your research interests as this will increase the chances of acceptance into an HDR program. Request advice from the administrative staff about the structure and content of your research proposal. Most universities have a web page detailing requirements and a Microsoft Word template.

\subsection{Locate an HDR Supervisor}

The HDR experience will be quite different to your undergraduate and postgraduate coursework study. You will be entering into a Master and Apprentice relationship [18], [2]. While there are policies and procedures that protect students' rights, in many ways you are beholden to the supervisor to navigate hurdles. That is not to say that the student does not drive their research. However, the level of supervisory experience a supervisor possesses and knowledge of your specific topic area and ability to give feedback effectively, varies greatly [2], [18]. Be aware that most HDR supervisors have limited time allocated in their workload for supporting their postgraduate students. Therefore, it is the student's responsibility to submit work on time and ensure they complete follow up work. It is worth taking the time to consider what it is that you value in a supervisor or mentor [1], [2] [3].

In my previous paper about my HDR journey the author outlined numerous supervisory approaches and the impact that power types had on my ability to seek clarification, advance my work, and obtain feedback. Think about the type of feedback you need, will accept and how you will build your confidence and make a strong start to the project [2].

Ask around about the HDR experience, reputation, domestic and international standing of the supervision team you are going to approach. If they are well known and at the pinnacle of their career, they will be busy, and this will affect their availability for consultation [2], [11].

It may not be an issue for you but if you feel you would need considerable time at the beginning, then ask the potential supervisor about their availability throughout the year. In my experience academic supervisors do not always state when they will be away or unavailable for consults. Consider what type of supervision you want and need [1]. Seek advice from colleagues or fellow students and the HDR section of the university [2], [11].

\subsection{Complete the HDR Admin Process}

The HDR Admin Process should be straightforward if you follow the instructions posted on the university website where you wish to study. If the website is in your second language seek assistance from the university to ensure you have understood requirements. In addition, seek guidance about writing personal statements and requesting letters of recommendation from employers, academic supervisors, or research collaborators. These people should know you well and be able to comment truthfully and favourably about your diligence, personality, and ability to work independently [19]. 
Prepare key questions to guide this process. The who, what, where when and how. Questions such as: Why do I want to study for a higher degree by research? How will I organise my time? What do I need to know before I apply? Speak with HDR students about their experiences at your proposed university prior to commencement. This is not always possible, but most universities display affirmations from students on their websites. Know the rules. Ascertain what type of support the university offers academically, accommodation and financial scholarships as this will be important for those people who study part-time as well as full-time candidates [2].

\section{Challenges Vs Opportunities}

One of the key challenges you will face is the expected imbalance of power in the relationship between yourself and your supervisor. With some careful planning and flexibility, you can transform this unique relationship into an opportunity to learn or enhance important workplace skills. Do not underestimate the importance of establishing a productive research relationship prior to commencement [2].

In a previous paper, the author reflected on the changing relationship between supervisor (Master) and apprentice (Student) [2]. There are several dimensions to be aware of: power relationships, communication and negotiation skills, organisation and finally managing technology effectively. Planning how you will communicate, engage productively, organise your workspace and practice as well as integrate technology prior to commencement will give you a sense of personal power and confidence.

\subsection{Power Relationships}

Before you formalise the supervision relationship, it is wise to find out how your supervisor prefers to work by asking them questions about frequency of meetings, managing milestones and whether they prefer to direct every task or leave it to you to drive the research journey. This information will help you decide if the relationship is a good fit [12].

At the beginning of the relationship your assumption will be that they possess expert power in your intended area of study. To prepare yourself for a more teacher directed, traditional model of learning, consider what scaffolding you will need [2]. For example. if you do not feel confident asking for help or setting meeting dates you should discuss this matter with the university prior to commencement of candidature.

\subsection{Communication, Collaboration and Negotiation}

Highly effective communication and negotiation skills are critical in a successful supervision relationship. At the university where you will be studying there are rules and regulations that need to be adhered to as they protect the student, academic supervisor, and the institution when misunderstandings or a breakdown in communication occurs.

Your supervisor, academic skills unit, or the university counselling service can provide advice about how to enhance your communication and negotiation skills [2]. Knowing how the relationship will be structured, the cultural expectations and the frequency of meetings, will keep communications open and both parties accountable for their role in the learning journey. As the author has mentioned previously, ensure that you engage with other postgraduate students, your friends, colleagues if you are working and most importantly your family. If you have worked hard to negotiate supportive practices with your family then you have already made a strong start to a project that can be isolating and solitary. Therefore, if you need assistance in this area may I suggest that you seek support from academic skills units, the library and counselling services that provide a discreet, confidential service.

\subsection{Organisation of Your Project}

A research project is an exciting pursuit if you are well organised and document success, failures and note adjustments you need to achieve outcomes you set. Organise your technology, applications, electronic folders so you can locate research papers, drafts, and feedback efficiently on your computer network. Ensure you save work on a cloud system which you can access anywhere. Do not forget to seek advice on a backup system should you lose your original work.

A dedicated workspace at home and on campus will help you to keep your mind on the job when getting ready to start the thesis journey. Universities offer support and access to technology devices in their libraries. Therefore, the author suggests that you discuss issues with access to technology or a dedicated workspace with your postgraduate research librarians.

\section{Technology and Digital Wellbeing?}

The technology solutions you decide to adopt when preparing to embark on the thesis journey affects how you manage your research. The author acknowledges, from experience and research practice, that the applications, video conferencing options will 
change over time, but you need to change with it. This is where your digital wellbeing needs to be a priority.

Digital wellbeing is a contemporary term for describing digital solutions to challenges by human and computer engagement which supports healthy, productive work practices including reflection and productive responses to social change [20].

Digital wellbeing is important to implement because it is more likely to alleviate stress. If you have access to technology to note down ideas whether using a range of input devices such as typing, voice dictation, or swipe and click, more common with tablets, one must ensure they know how to use it effectively [20].

If you are unable to logon, click, swipe or use your input devices as well as storage when you need to this can cause 'digital stress'. Despite universities' best efforts to support students, particularly with regards to digital solutions, there are in built assumptions that students will know how to use the technology made available or just post online static resources such as uploaded written instructions [20], [21]. Digital stress impedes one's ability to think, process ideas and impact your ability to conduct experiments and write. Up-to-date technology, apps, networks, backup systems are essential technology you should set up to suit your working style prior to commencing research.

You may be tempted to use one of the automatic referencing systems available to you. I would be cautious here. Learn how to cite as you write consistently as it will save you a lot of misery as you progress through the thesis - author's experience was that it was better to learn to integrate references progressively as there was no single automatic referencing system that did not need manual intervention.

\section{Conclusion}

On the outset, the HDR application process looks straightforward for postgraduate students. Universities provide copious information on websites, with the best intentions, to scaffold the lengthy journey to 'open the door' to your MPhil or PhD study. However, as the author has articulated in the paper that there is considerable preparation required before you complete the online application form.

Prepare all your paperwork such as: an employment history, curriculum vitae, list of publications and verified academic transcripts. It is good practice to prepare a personal statement in which you give the reader an impression of who you are and why you want to study a higher degree by research with your chosen university. This documentation that you will write also gives a first impression of your academic writing.

The research proposal may seem like a daunting task. However, most universities will provide guidance. Sometimes potential supervisors may inform you about what they require from you, to make a decision on whether your proposed project fits with their program of research.

One of the most important aspects of the application process is your ability to communicate, negotiate and show willingness to collaborate with the university community supporting this journey. Communication with potential supervisors needs to have a clear objective, namely, to enquire about their availability to supervise your MPhil or PhD. The research proposal is part of the preparation you need to complete prior to finalising an online application.

Getting organised which includes finding a space where you will work either on campus or in your home, regular work time and relevant technology will help you ease into this new way or thinking and working. If you find your digital wellbeing or literacy is lacking, take responsibility for upskilling in using technology responsibly and effectively. Request help and guidance from university services and your supervisor.

Finally, do not be put off if you do not get into your preferred course or university. Evaluate what you have learned in this journey and consider how your understanding, approach to research and community skills have transformed.

In the next paper in this series the author will address what to expect and prepare for at the beginning of the thesis.

\section{References}

[1] M.B. Fisher, "HDR Supervision 2: Reflection on Support of a Mature Aged Student with Diverse Needs", International Journal of Technology and Inclusive Education (IJTIE), Special Issues, Vol. 3, Issue 1, 2016. https://infonomics-society.org/wp-content/uploads/ijtie/pu blished-papers/special-issue-volume-3-2016/HDR-Superv ision-2-Reflection-on-Support-of-a-Mature-Aged-Studentwith-Diverse-Needs-1.pdf. (Access Date: 12 January 2022).

[2] M. Fisher, 'The HDR Process: Reflection on the Motivational Factors, Academic Model, Influences and Challenges That Enabled an Academic to Complete Her Thesis Part-Time', International Journal for Infonomics (IJI), Vol. 13, 2020, pp. 2018-2025. DOI:10.20533/iji. 1742.4712.2020.0209.

[3] C. Wilkinson, "Imposter syndrome and the accidental academic: an autoethnographic account", International Journal for Academic Development, Vol. 25, (4), Routledge Taylor and Francis, Online, 2020, pp. 363-374.

[4] A. Wain, "Learning Through Reflection", British Journal of Midwifery, Vol. 25, (10), October 2017, pp. 662666.

[5] R. Middleton, 'Critical reflection: the struggle of a practice developer', International Practice Development Journal, Vol. 7, Issue 1, 5 April2017, pp. 1-6. DOI: 10.19043/ipdj.71.004. 
[6 ] Kolb, Alice Y. and Kolb, David A. (2017) 'Experiential Learning Theory as a Guide for Experiential Educators in Higher Education," Experiential Learning and Teaching in Higher Education: Vol. 1 : No. 1 , Paper 7. https://nsuworks .nova.edu/elthe/vol1/iss1/7. (Access Date: 12 January 2022).

[7] S. Eschenbacher and T. Fleming, "Transformative dimensions of lifelong learning: Mezirow, Rorty and COVID-19", International Review of Education, Springer, DOI: $10.1007 / \mathrm{s} 11159-020-09859-6$.

[8] A. Sverdilk, C. Nathan. and L. McAlpine, "PhD Imposter Syndrome: Exploring Antecedents, Consequences and Implications for Doctoral Well-Being", International Journal of Doctoral Studies, Vol. 15, 2020, pp. 137-758.

[9] V. Rowtho, S. Gopee and A. Hingun, "Doctoral boot camps: from military concept to andragogy", Education and Training, Vol. 62, (4),2020, pp. 379-392.

[10] Knowles, Malcolm S., et al. The Adult Learner: The Definitive Classic in Adult Education and Human Resource Development, Taylor and Francis Group, 2015.

[11] L. Jabre, C. Bannon, J.S.P. McCain, Y. Eglit, 'Ten simple rules for choosing a $\mathrm{PhD}$ supervisor, PLoS Computational Biology, Vol. 17 (9), 2021. DOI:10.1371/ journal.pcbi.1009330.

[12] H. Aguinis, M.S. Nesler, B.M. Quigley, S.J. Lee and J.T. Tedeschi, 'Power Bases of Faculty Supervisors and Educational Outcomes for Graduate Students, The Journal of Higher Education, Vol. 67, (3), 1996, pp. 267-297.

[13] L. DeAngelis, 'Enabling the Exploration of Disorienting Dilemma in the Classroom', Journal of Education, 2021, pp. 1-16.

[14] A. Greenspon, '9 Things you should consider before embarking on a $\mathrm{PhD}$, Elsevier Connect, Updated 2021. Located at: https://www.elsevier.com/connect/9-thingsyou-should-consider-before-embarking-on-a-phd. (Access Date: 12 January 2022).

[15] D.K. Sokol, 'Is a $\mathrm{PhD}$ the right option for you? in The Guardian, 12 September 2012, https://www.theguardian.co $\mathrm{m} /$ careers/phd-right-career-option. (Access Date: 12 Janua ry 2022$)$.

[16] S.K. Ratan, T. Anand and J. Ratan, 'Formulation of research question - Stepwise approach, Journal of Indian Association of Pediatric Surgeons, Vol. 24, Issue 1, 2019, pp. 15-20.

[17] J. Berman, 'Utility of a conceptual framework within doctoral study: A researcher's reflections', Issues in Educational Research, 23 (1), 2013, pp. 1-18.

[18] S. Harrison and C. Grant, "Exploring of new models of research pedagogy: time to let go of master-apprentice style supervision?" Teaching in Higher Education, Vol. 20, (5), 2015, pp. 556-566.

[19] D.C. Appleby and K.M. Appleby, 'Kisses of Death in the Graduate School Application Process', Teaching of
Psychology, Vol. 33, No. 1, 2009, pp. 19-24. DOI: 10.1207 /s15328023top3301_5.

[20]_M.B. Fisher, 'Strategies to Improve your Digital Wellbeing Using ePortfolios - An Introduction, in The eBook of Shortened Peer Reviewed Papers, ePortfolios Australia 2020 (2) Conference and Forum, 27 October.

[21] M.A.M. Hashim, I. Tlemsani and R. Matthews, 'Higher education strategy in digital transformation', Education and Information Technologies, 14 September 2021. DOI: 10.1007/s10639-021-10739-1. 